\title{
EX-SITU TEM STUDY OF AU ISLANDS
}

C.E. Kliewer, J.L. Robbins, A. Malek

ExxonMobil Research \& Engineering, Rte 22 East, Annandale, NJ 08801

The need to adequately define the microstructure of materials under "real life" conditions is of increasing importance in both the scientific and industrial communities. Over the last few years, more sophisticated ex-situ TEM techniques have been employed to improve this knowledge base. ${ }^{1-4}$

A dedicated reactor system developed at ExxonMobil for "exsitu" TEM was used to study the effect of temperature on Au particles deposited on a silica support (Figure 1).

In this study, Au foil was used to vapor deposit metal particles onto a standard, 200 mesh, holey-carbon-coated TEM grid. This was accomplished via a high temperature ex-situ treatment of the $\mathrm{Au}$ foil under flowing hydrogen. Subsequent to the deposition, the TEM grid was transferred under inert conditions into a Philips CM200F TEM/STEM, where randomly selected regions were characterized (Figure 2a). Several high temperature "ex-situ" treatments of the TEM sample at in flowing hydrogen at followed (Figures $2 b$ and $2 c$ ). This technique provides us with the opportunity to examine of the same Au particles over time with each treatment. From these images, we observed that nearby particles were able to interact with each other and grow.

References:

1. L.F. Allard et. al., Proceedings Microscopy \& Microanalysis 3 Supplement 2 (1997) 595

2. C.E. Kliewer et. al., Proceedings Microscopy \& Microanalysis 5 Supplement 2 (1999) 926

3. C.E. Kliewer et. al., Proceedings Microscopy \& Microanalysis 6 Supplement $2(2000) 378$

4. C.E. Kliewer et. al., Proceedings Microscopy \& Microanalysis 7 Supplement 2 (2001)1214 


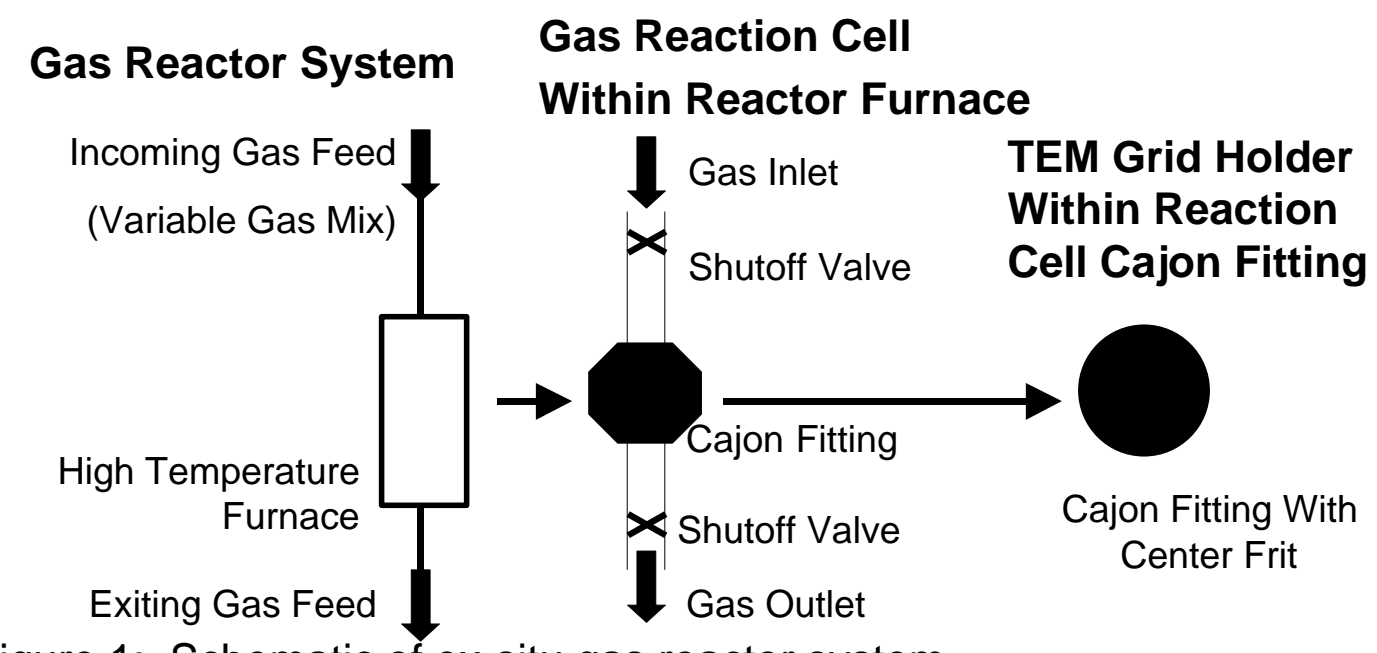

Figure 1: Schematic of ex-situ gas reactor system.

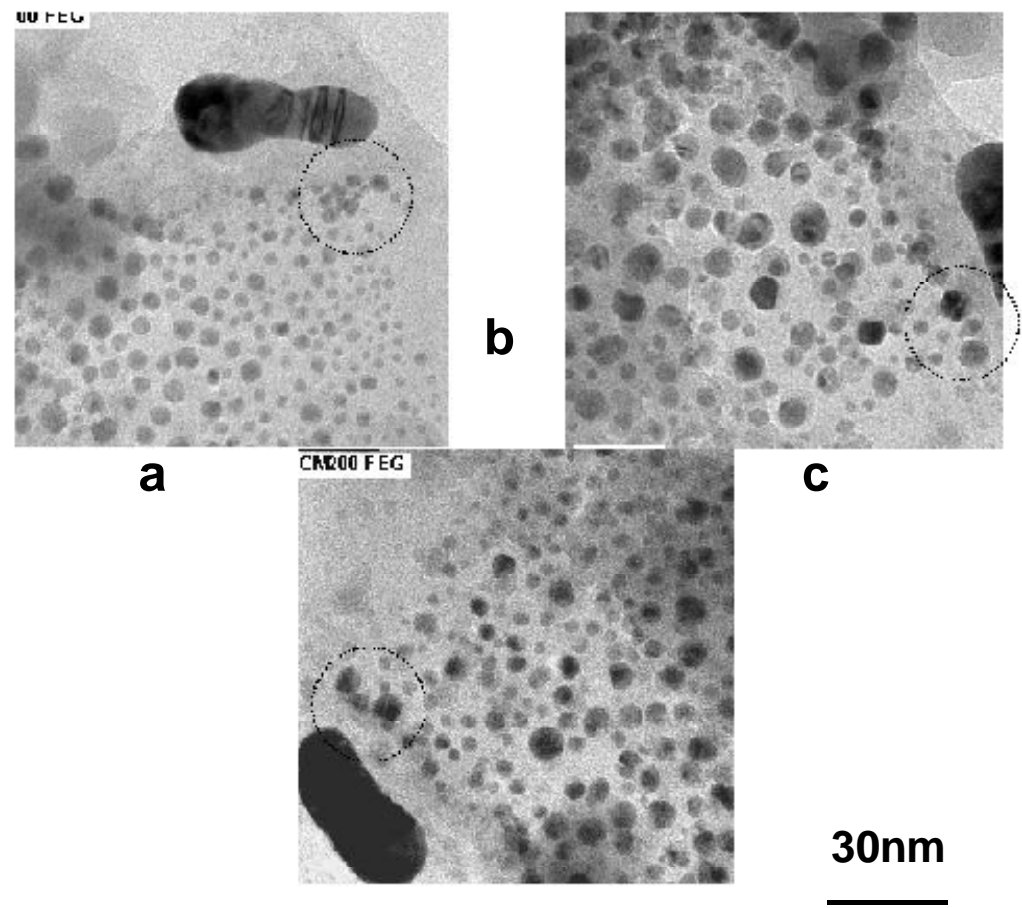

Figure 2: BFTEM image showing Au particles on $\mathrm{SiO}_{2}$ substrate (a) $4 \mathrm{hr}$. $\mathrm{H}_{2}$-treatment @ $450^{\circ} \mathrm{C}$ (b) 0.1hr. $\mathrm{H}_{2}$-treatment @600 $\mathrm{H}_{2}$-treatment @600ㄷ. 